\title{
Good Practices in Mental Health
}

\author{
Judy RenSHAw, Director, Good Practices in Mental Health
}

Good Practices in Mental Health (GPMH) is a national charity set up to disseminate information about local mental health services which are found to work well. Its general aim is to promote and assist the development of good mental health services. By providing an exchange of information about effective services in both hospitals and the community, GPMH encourages others to build on what is already proving successful. GPMH developed from a survey of mental health in big cities carried out by the International Hospital Federation (IHF) and was set up in 1977 with the support of the IHF, MIND and the King's Fund. It has the backing of all the major professional organisations concerned with mental health in the United Kingdom, the World Health Organization and the World Federation for Mental Health internationally. It is now funded mainly by the DHSS; some funding comes from the London Boroughs Grants Committee and charitable sources. There are three units within the organisation: information, development and evaluation.

\section{Information}

The information service exists principally to respond to enquiries from service providers. The GPMH data bank offers practical information about a wide variety of individual mental health services. Schemes are drawn from both the statutory and voluntary sectors and may be either small-scale projects or components of larger services. Information is stored about a wide range of innovative services for mentally ill people and their families, e.g. service planning, cooperation between health, local authority and voluntary organisations, support services such as housing, employment and day care, respite care, self-help, advocacy and consumerism. Information is provided for mental health and social service planners and other key professionals in the field who would like to learn from the experience of others. It is especially useful to mental health practitioners and planners who are considering setting up new services, who want to improve existing ones and are looking for new ideas.

GPMH has produced publications and information packs on topical issues, such as community mental health centres/teams, advocacy, the users' movement, asylum and housing. GPMH publishes two newsletters: Ordinary Housing, which focuses on housing issues and is jointly produced by GPMH and MIND South East; and New Directions, the development team's newsletter.

Conferences and workshops on specific topics are organised, often in conjunction with other organisations, as a means of facilitating the dissemination of information on developments in the mental health field.

\section{Development}

The emphasis of the development team's work has changed over recent years. Orginally the objective was to stimulate studies of local mental health resources throughout the country. Local studies are planned and carried out by multi-agency groups who represent mental health interests and services in a district. Development staff help these groups to establish their criteria for good practice before embarking on a study and continue to assist throughout the study period.

GPMH is currently involved in the development of mental health forums. In some areas inter-agency forums have been the natural progression from a GPMH local study and provide an opportunity for professionals and service users to discuss jointly existing and future services. An important aim of the team is to ensure that users' views are represented in planning and development of mental health services. GPMH has addressed this issue via its own input into the planning of services; through seminars and workshops and also by the establishment of user forums. Funding from the London Borough Grants Unit for the development of user forums has enabled GPMH to gain valuable experience of user involvement and self advocacy.

\section{Evaluation}

The evaluation team was established to monitor and evaluate a series of centrally-funded development projects and to disseminate information about them. The projects have been funded with the intention of providing a service for people with long-term or serious mental illness living in the community. About half are community mental health teams; the rest vary, from a psychiatric service for single homeless 
people to a service for carers of elderly mentally ill people. The team assists the projects by providing them with useful information and by running workshops on important issues. The evaluation is focused on methods of providing an improved quality of life for people with long-term mental illness and aims to produce some general lessons which may be helpful to others who attempt similar schemes.

\section{GPMH consultancy service}

GPMH is a non-partisan organisation. It has no allegiance with any particular agency, profession or faction within the mental health field. A 'neutral' stance is maintained from which it is possible to listen to the views of all those involved. However, a set of principles may be identified as the basis of GPMH's work in promotion of better mental health care. The principles for service include:

(1) clarity of service objectives

(2) responsiveness to individual needs and circumstances

(3) comprehensiveness across type of need

(4) continuity over time

(5) minimal disruption or restriction to a person's life

(6) accessibility to all

(7) social acceptability

(8) coordination with other local agencies and services

(9) involvement of the wishes of users and carers

(10) appropriate use of resources to maximise effectiveness and efficiency.

The principles, elaborated at a number of different levels of generality, are set out at length in the annual Report for 1987.

The consultancy service works from its 'nonpartisan' stance to assist planners, managers and staff teams to develop better mental health care. The information bank provides a rich source of knowledge in addition to 'networks' of contacts working in particular areas. Topics upon which GPMH has special expertise include:

\section{(1) Setting service objectives}

Managers and teams usually find it difficult to focus on the objectives of their work and its effect on consumers. A number of workshops and exercises have been developed to assist in this and to stimulate plans and activities which are orientated towards the consumer. These also provide a useful tool in the development of effective teamwork and better mutual understanding.

\section{(2) Monitoring and evaluation}

GPMH staff have experience of a wide variety of monitoring and evaluation strategies. They range from the application of 'Off the Shelf' instruments for assessment of outcomes, services and costs to action research approaches and assistance to projects who wish to undertake self-monitoring. Evaluation services should always aim to bear in mind the objectives of the service and the different viewpoints of the various interested parties.

\section{(3) Case management}

With the Griffiths report - and anticipated Government response-high on planning agendas, case management is becoming an important feature of developing services. Good community care inevitably involves a range of agencies, which can provide different elements of the total package. Coordination of these elements at the individual level is essential if services are to appropriately meet the needs of individual people.

GPMH has worked with schemes who have operated a variety of case management models and is able to discuss and advise upon the types of model which might best suit local need.

\section{(1) Involvement of service users and self-advocacy}

The importance of user involvement in mental health services is now widely recognised. Most planning teams state a wish to incorporate the views of users but few know how to realise this in practice. GPMH has assisted the development of user groups and forums, on the basis of both individual services and district-wide. Learning from these has provided valuable experience, from which we can guide and assist others.

\section{(5) Day care}

What is the purpose of day care? Is it training, employment, occupation, education, therapy, leisure, social activity - or a combination of these? Should the different functions be provided by a single centre or a number of different centres for the needs of different people? Who should run them? How do these fit with other local facilities and the community? GPMH can assist local areas to examine their needs for day care and to plan appropriately for local people. Models of a wide range of facilities are available in the data bank.

Further topics of interest include residential provision in supported ordinary housing, strategies for working with people who have long-term needs and resettlement from hospital.

Good Practices in Mental Health can be contacted at 380-384 Harrow Road, London W9 2HU, telephone 01-289 2034/3060 for information requests, publications or development enquiries. 